\title{
A Disease That Can Be Debilitating: Chronic Spontaneous Urticaria
}

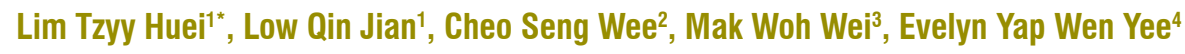

\author{
${ }^{1}$ Department of Internal Medicine, \\ Hospital Sultanah Nora Ismail, \\ Batu Pahat, Johor, Malaysia \\ 2 Department of Internal Medicine, \\ Hospital Lahad Datu, Lahad Datu, \\ Sabah, Malaysia \\ ${ }^{3}$ Department of Internal Medicine, \\ Hospital Bentong, Bentong, Pahang, Malaysia \\ ${ }^{4}$ Department of Dermatology, \\ Hospital Pakar Sultanah Fatimah, \\ Muar, Johor, Malaysia.
}

\section{*Corresponding author's email: savy117@gmail.com}

Received: 18 March 2021

Accepted: 19 August 2021

DOI: https://doi.org/10.51200/bjms.vi.2923

Keywords: chronic spontaneous urticarial, debilitating, disease

\section{ABSTRACT}

Chronic spontaneous urticaria is characterized by recurrent urticaria with or without angioedema for more than six weeks with no apparent external triggers. It affects up to one per cent of the general population and it is common in primary care settings or emergency services. Chronic spontaneous urticaria can be debilitating, difficult to treat, and frustrating for patients and doctors. Here, we described our experience of treating five patients with recalcitrant chronic spontaneous urticaria. Through this short communication, we would like to increase awareness of the general treatment approach to chronic spontaneous urticaria in primary care and specialist services.

\section{INTRODUCTION}

Chronic spontaneous urticaria is not triggered by identifiable factors. About one-half of patients with chronic spontaneous urticaria have associated angioedema which usually affects the cheeks, lips, periorbital areas, genitals, and extremities. Chronic spontaneous urticaria is a self-limiting disease in most patients with an average disease duration of two to five years. Up to 20 per cent of patients have persistent symptoms beyond five years (Van Der Valk et al., 2002). Here, we described our experience of treating five recalcitrant chronic spontaneous urticaria patients with up to four times the standard dose of secondgeneration antihistamine, leukotriene receptor antagonist, and subsequently omalizumab. 


\section{Treatment Experience}

Patients' urticaria symptoms were evaluated by using the Urticaria Activity Score over seven days (UAS7 Score, Table 1).

Table 1 Urticaria Activity Score over seven days (UAS7 Score) (Zuberbier et al., 2018)

\begin{tabular}{lll}
\hline Score & Wheals & Pruritus \\
\hline 0 & None & None \\
1 & Mild $(<20$ wheals/ $24 \mathrm{hr})$ & Mild (present but not annoying or troublesome) \\
2 & Moderate $(20-50$ wheals/ $24 \mathrm{hr})$ & $\begin{array}{l}\text { Moderate (troublesome but does not interfere with normal daily activity } \\
\text { or sleep) }\end{array}$ \\
3 & $\begin{array}{l}\text { Intense (50 wheals/ } 24 \mathrm{hr} \text { or } \\
\text { large confluent areas of wheals) }\end{array}$ & $\begin{array}{l}\text { Intense (severe pruritus, which is sufficiently troublesome to interfere with } \\
\text { normal daily activity or sleep) }\end{array}$ \\
\hline
\end{tabular}

Sum of score: 0 - 6 for each day is summarized over 1 week (maximum 42).

UAS7 $<7$ may be evaluated as wellcontrolled, $7-15$ as mild, $16-27$ as moderate, $28-42$ as severe activity urticaria.

Patient 1 was a 32-year-old female who had chronic spontaneous urticaria which was unresponsive to loratadine $10 \mathrm{mg}$ QID and montelukast $10 \mathrm{mg}$ ON. After the first dose of $\mathrm{S} / \mathrm{C}$ omalizumab $300 \mathrm{mg}$, her chronic urticaria symptoms were generally improved (UAS7 score from 20 to 6 ). She received her second dose of omalizumab $300 \mathrm{mg}$ after one month and she experienced partial hearing loss in both her ears after one week of injection. The symptom of partial hearing loss resolved after one month. Although a further improvement was seen in her UAS7 score (from18 to 6), omalizumab was discontinued as it was likely she developed drug-induced hearing loss after consultation with the ENT team. The patient's urticaria symptoms recurred about two months after stopping omalizumab, but it was generally better with a UAS7 score of 10 until now.

Patient 2 was a 49-year-old female with underlying endometriosis. She had chronic spontaneous urticaria which was unresponsive to bilastine $40 \mathrm{mg} \mathrm{BD}$ and montelukast $10 \mathrm{mg}$ ON. After the first dose of $\mathrm{S} / \mathrm{C}$ omalizumab $300 \mathrm{mg}$, her chronic urticaria symptoms had improved significantly (UAS7 score from 22 to 6). However, she developed worsening dysmenorrhea two weeks after the omalizumab injection. As a result, she declined subsequent doses of omalizumab. The patient's urticaria symptoms recurred after four weeks of stopping omalizumab with a UAS7 score of 12 to 14 .

Patient 3 was a 24-year-old male with chronic spontaneous urticaria which was unresponsive to cetirizine $10 \mathrm{mg}$ QID and montelukast $10 \mathrm{mg} \mathrm{ON}$. He had to go to the emergency department once a month for IV hydrocortisone. He was given $\mathrm{S} / \mathrm{C}$ omalizumab $150 \mathrm{mg}$ monthly for two months and he responded well to the treatment (UAS7 score from 24 to 7). However, urticaria symptoms recurred six weeks after stopping omalizumab with a UAS7 score of 28.

Patient 4 was a 59-year-old female with chronic spontaneous urticaria which was unresponsive to loratadine $20 \mathrm{mg} \mathrm{BD}$ and montelukast $10 \mathrm{mg}$ ON. She was given $\mathrm{S} / \mathrm{C}$ omalizumab $150 \mathrm{mg}$ for two doses and she responded well to the treatment (UAS7 score from 25 to 5). However, urticaria symptoms recurred eight months after stopping omalizumab with a UAS7 score of 15 .

Patient 5 was a 49-year-old female with chronic spontaneous urticaria which was unresponsive to loratadine $10 \mathrm{mg}$ QID and montelukast $10 \mathrm{mg}$ ON. She was given $\mathrm{S} / \mathrm{C}$ 
omalizumab $150 \mathrm{mg}$ monthly for one dose and her urticaria symptoms were controlled to date (UAS7 score from 2 to 5 ).

Some autoimmune disorders are more prevalent in patients with chronic spontaneous urticaria, for example, thyroid disorders, systemic lupus erythematosus, celiac disease, and Sjogren syndrome (Confino-Cohen et al., 2012; Kim et al., 2017; Lapi et al.,2016). All our patients with chronic spontaneous urticaria had no associated autoimmune symptoms, with normal thyroid function tests and negative ANA tests.

Evidence suggests that chronic spontaneous urticaria can have a substantial impact on patients' quality of life, mental health, and the ability to perform daily tasks (Maurer et al.,2017). The study has shown that some patients with chronic spontaneous urticaria had concurrent posttraumatic stress disorder resulting from past traumas and developed psychiatric comorbidity (Hunkin et al.,2012). A stepwise approach to treatment is recommended by major guidelines (Table 2 ) (Bernstein et al., 2014; Zuberbier et al., 2018). A difference between the 2018 international guidelines and the 2014 American practice parameters is the preference of the international guidelines to use a single antihistamine for up-dosing. Whereas the American guidelines suggest combining two different second-generation antihistamines when up-dosing.

Table 2 Comparison of 2018 International Guideline (left side) and 2014 American Guideline (right side) (Bernstein et al., 2014; Zuberbier et al., 2018)

\begin{tabular}{|c|c|c|}
\hline & The EAACI/ WAO Guideline & The AAAAI/ ACAAI Guideline \\
\hline $\begin{array}{l}\text { Basic } \\
\text { Treatment }\end{array}$ & \multicolumn{2}{|c|}{ Avoidance of triggers and relevant physical factors } \\
\hline Step 1 & $\begin{array}{l}\text { Monotherapy with 2nd generation } \\
\text { Antihistamine }\end{array}$ & Monotherapy with 2nd generation Antihistamine \\
\hline & If inadequate control after $2-4$ weeks or earlier & Assess for patient's tolerance and efficacy \\
\hline Step 2 & $\begin{array}{l}\text { Increase 2nd generation Antihistamine dose (up } \\
\text { to } 4 \times \text { ) }\end{array}$ & $\begin{array}{l}\text { One or more of the following: } \\
\text { Dose advancement of } 2 \text { nd generation antihistamine } \\
\text { used in Step } 1 \\
\text { Add another } 2 \text { nd generation of antihistamine } \\
\text { Add } \mathrm{H} 2 \text {-antagonist } \\
\text { Add Leukotriene receptor antagonist } \\
\text { Add } 1 \text { st generation antihistamine to be taken at } \\
\text { bedtime. }\end{array}$ \\
\hline & If inadequate control after $2-4$ weeks or earlier. & Assess for patient's tolerance and efficacy \\
\hline Step 3 & $\begin{array}{l}\text { Add-on to } 2 \text { nd generation antihistamine: } \\
\text { Omalizumab }\end{array}$ & $\begin{array}{l}\text { Dose advancement of potent antihistamine as } \\
\text { tolerated. }\end{array}$ \\
\hline$\sqrt{1}$ & If inadequate control after $2-4$ weeks or earlier. & Assess for patient's tolerance and efficacy \\
\hline Step 4 & $\begin{array}{l}\text { Add-on to 2nd generation antihistamine: } \\
\text { Cyclosporin }\end{array}$ & Add other agents: Omalizumab or cyclosporin \\
\hline
\end{tabular}

EAACl, European Academy of Allergology and Clinical Immunology; WAO, World Allergy Organization. AAAAl: American Academy of Allergy, Asthma, and Immunology; ACAAl: American College of Allergy, Asthma, and Immunology. 
Second-generation $\mathrm{H} 1$ antihistamines are first-line treatment, Up to $60 \%$ of patients remain symptomatic despite receiving $\mathrm{H} 1$ antihistamines at up to four times higher than the standard dose. Such patients may need additional treatments such as leukotriene receptor antagonists, cyclosporin, oral corticosteroid, or Omalizumab. Omalizumab is a monoclonal antibody directed against $\lg \mathrm{E}$, which was approved in the United States in 2014 for the treatment of patients 12 years of age and older with recalcitrant chronic spontaneous urticarial (Wu et al., 2015). Short-term systemic glucocorticoids may be considered to achieve temporary control of symptoms during severe exacerbations of urticaria that impair quality of life. Clinical trials have demonstrated that omalizumab significantly reduced (up to $44 \%$ to $52 \%$ ) the UAS7 weekly itch and wheal scores in patients with chronic spontaneous urticaria not responsive to the standard dose of $\mathrm{H} 1$ antihistamines (Zhao et al., 2016). Even though omalizumab is generally well tolerated, adverse events have been reported. Common ones include headache, sinusitis, arthralgia, and local site reaction (Vestergaard et al., 2017). Omalizumab-associated hearing loss or dysmenorrhea has not been reported in the literature.

Patients with chronic spontaneous urticaria should be referred for specialist care in the following conditions:

1. Symptoms are not controlled with step 1 or require prolonged treatment with glucocorticoids.

2. An underlying disorder is suspected (such as autoimmune disorders, thyroid disorder).

3. Signs or symptoms suggest urticarial vasculitis, such as urticarial lesions that leave residual ecchymotic lesions or are associated with fever/ joint pain.

\section{CONCLUSION}

Patients with chronic spontaneous urticaria are often frustrated as it can significantly impair their quality of life. Apart from the treatment with an oral antihistamine, leukotriene receptor antagonist, or omalizumab, it is important to look for aggravating factors such as NSAIDs, heat, cold, sunlight, friction from clothing, alcohol, stress, concomitant infections, and menstruation. Understanding and learning to avoid those relevant aggravating factors are critical components of successful management.

\section{CONFLICT OF INTEREST}

The authors declare that they have no competing interests in publishing this article.

\section{REFERENCES}

Bernstein, J. A., Lang, D. M., Khan, D. A., Craig, T., Dreyfus, D., Hsieh, F., \& Wallace, D. (2014). The diagnosis and management of acute and chronic urticaria: 2014 update. Journal of Allergy and Clinical Immunology, 133 (5), 1270 - 1277. https://doi.org/10.1016/j. jaci.2014.02.036

Confino-Cohen, R., Chodick, G., Shalev, V., Leshno, M., Kimhi, O., \& Goldberg, A. (2012). Chronic urticaria and autoimmunity: associations found in a large population study. Journal of Allergy and Clinical Immunology, 129 (5), 1307 - 1313. https://doi.org/10.1016/j. jaci.2012.01.043

Hunkin, V., \& Chung, M. C. (2012). Chronic idiopathic urticaria, psychological co-morbidity and posttraumatic stress: the impact of alexithymia and repression. Psychiatric Quarterly, 83 (4), 431 - 447. https://doi. org/10.1007/s11126-012-9213-7

Kim, Y. S., Han, K., Lee, J. H., Kim, N. I., Roh, J. Y., Seo, S. J., \& Park, Y. M. (2017). Increased risk of chronic spontaneous urticaria in patients with autoimmune thyroid diseases: a nationwide, population-based study. Allergy, Asthma \& Immunology Research, 9 (4), 373 - 377. https://doi.org/10.4168/aair.2017.9.4.373 
Lapi, F., Cassano, N., Pegoraro, V., Cataldo, N., Heiman, F., Cricelli, I., \& Vena, G. A. (2016). Epidemiology of chronic spontaneous urticaria: results from a nationwide, population-based study in Italy. British Journal of Dermatology, 174 (5), 996 - 1004. https://doi.org/10.1111/bjd.14470

Maurer, M., Abuzakouk, M., Bérard, F., Canonica, W., Oude Elberink, H., Giménez-Arnau, A., \& Balp, M. M. (2017). The burden of chronic spontaneous urticaria is substantial: real-world evidence from ASSURECSU. Allergy, 72 (12), 2005 - 2016. https://doi. org/10.1111/all.13209

Van Der Valk, P. G. M., Moret, G., \& Kiemeney, L. A. L. M. (2002). The natural history of chronic urticaria and angioedema in patients visiting a tertiary referral centre. British Journal of Dermatology, 146 (1), 110 - 113. https://doi. org/10.1046/j.1365-2133.2002.04582.x

Vestergaard, C., Toubi, E., Maurer, M., Triggiani, M., Ballmer-Weber, B., Marsland, A., \& Giménez-Arnau, A. (2017). Treatment of chronic spontaneous urticaria with an inadequate response to $\mathrm{H}$ 1-antihistamines: an expert opinion. European Journal of Dermatology, 27 (1), 10 - 19. https://doi. org/10.1684/ejd.2016.2905
Wu, K. C., \& Jabbar-Lopez, Z. K. (2015). Omalizumab, an Anti-lgE mAb, receives approval for the treatment of chronic idiopathic/ spontaneous urticaria. Journal of Investigative Dermatology, 135 (1), 13 - 15. https://doi.org/10.1038/jid.2014.362

Zhao, Z. T., Ji, C. M., Yu, W. J., Meng, L., Hawro, T., Wei, J. F., \& Maurer, M. (2016). Omalizumab for the treatment of chronic spontaneous urticaria: A meta-analysis of randomized clinical trials. Journal of Allergy and Clinical Immunology, 137 (6), 1742 - 1750. https:// doi.org/10.1016/j.jaci.2015.12.1342

Zuberbier, T., Aberer, W., Asero, R., Abdul Latiff, A. H., Baker, D., Ballmer-Weber, B., \& Maurer, M. (2018). The EAACl/GA²LEN/ EDF/WAO guideline for the definition, classification, diagnosis and management of urticaria. Allergy, 73 (7), 1393 - 1414. https:// doi.org/10.1111/all.13397 
